\title{
CONSTITUTIVE EXPRESSION OF CYCLOOXYGENASE 2 TRANSGENE IN HEPATOCYTES PROTECTS AGAINST LIVER INJURY
}

\section{Mayoral R. ${ }^{1}$, Mollá B. ${ }^{2}$, Flores J. M. ${ }^{3}$ Boscá L. ${ }^{{ }^{*}}$, Casado M. ${ }^{2}$ \& Martín-Sanz P. ${ }^{{ }^{*}}$}

From the ${ }^{1}$ Instituto de Investigaciones Biomédicas Alberto Sols CSIC-UAM, Madrid, Spain $^{2}$ Instituto de Biomedicina de Valencia, IBV-CSIC, Valencia, Spain and ${ }^{3}$ Departamento de Medicina y Cirugía Animal, Facultad de Veterinaria, Universidad Complutense, Madrid, Spain. Centro de Investigación Biomédica en Red de Enfermedades Hepáticas y Digestivas (Ciberehd).

This work was supported by grants SAF2007-60551, SAF2005-1758 and S-BIO0283/2006. B. M. was supported by grant of FIS-RECAVA RD06/0014/0025. Ciberehd is funded by the Instituto de Salud Carlos III.

*Address reprint requests to: Paloma Martin-Sanz, Instituto de Investigaciones Biomédicas Alberto Sols, Consejo Superior de Investigaciones Científicas, Arturo Duperier 4, 28029 Madrid, Spain.E-mail:pmartins@iib.uam.es; fax: 34 914972748,or to: Lisardo Boscá, Instituto de Investigaciones Biomédicas Alberto Sols, Consejo Superior de Investigaciones Cientificas, Arturo Duperier 4, 28029 Madrid, Spain. E-mail:lbosca@iib.uam.es; fax:34914972748

Running head: COX-2 protects against liver injury

Keywords: prostaglandins, lipopolysaccharide, concanavalin A, inflammation, apoptosis. 


\section{ABSTRACT}

The effect of COX-2-dependent prostaglandins (PGs) in acute liver injury has been investigated in transgenic mice that express human COX-2 in hepatocytes. We have used three well established models of liver injury: Lipopolysaccharide injury in D-galactosamine preconditioned mice (LPS/D-GalN), the hepatitis induced by concanavalin A (ConA) and the proliferation of hepatocytes in regenerating liver after partial hepatectomy (PH). Our data demonstrate that PGs synthesis decreases in hepatocytes the susceptibility to LPS/D-GalN or ConA-induced liver injury as deduced by significant lower levels of the pro-inflammatory profile and plasmatic aminotransferases in transgenic mice, an effect suppressed by COX-2 selective inhibitors. These transgenic animals express higher levels of anti-apoptotic proteins and exhibit activation of proteins implicated in cell survival, such as Akt and AMP-kinase after injury. The resistance to LPS/D-GalN induced liver apoptosis involves an impairment of procaspase 3 and 8 activation. Protection against ConA-induced injury implies a significant reduction in necrosis. Moreover, hepatocyte commitment to start replication is anticipated in $\mathrm{Tg}$ mice after $\mathrm{PH}$, due to the expression of PCNA, cyclin D1 and E. These results show, in a genetic model, that tissue-specific COX-2 dependent PGs exert an efficient protection against acute liver injury by an antiapoptotic/antinecrotic effect and by accelerated early hepatocyte proliferation.

Keywords: prostaglandins, lipopolysaccharide, concanavalin A, inflammation, apoptosis. 


\section{INTRODUCTION}

The acute or chronic liver injury, caused by viral infection, autoimmune reactions, alcohol ingestion, or the use of certain drugs, results in severe pathologies including fulminant hepatitis, cirrhosis and hepatocellular carcinoma (HCC). Chronic hepatitis is a prolonged inflammatory process, with inflammatory cells infiltrating the liver parenchyma and triggering hepatocyte death. Persistent hepatocyte cell death is followed by a regenerative response in which viable hepatocytes are stimulated to proliferate to restore the loss of hepatic parenchyma [1].

Cyclooxygenase-1 (COX-1) and -2 catalyze the first step in prostanoid biosynthesis [2]. COX-1 is constitutively expressed in many tissues and seems to be involved in the housekeeping function of prostaglandins (PGs) [3], whereas COX-2 is induced by a variety of stimuli such as growth factors, pro-inflammatory stimuli, hormones and other cellular stresses [4]. Adult hepatocytes fail to induce COX-2 expression regardless of the pro-inflammatory factors used; however, Kupffer, stellate, immortalized mouse liver cells and fetal hepatocytes retain the ability to express COX-2 upon stimulation with LPS and pro-inflammatory cytokines $[5,6]$. In addition to this, we reported that partial hepatectomy $(\mathrm{PH})$ induced COX-2 in hepatocytes and this contributed to the progression of cell cycle after PH [7, 8]. Expression of COX-2 has been also detected in human and animal models of cirrhosis [9], after hepatitis B and C virus infection [10, 11], in hepatoma cell lines [12] and in well-differentiated HCC [13].

Despite these observations, the question of whether COX-2 expression is sufficient to induce tumorigenesis and the contribution of COX-2-dependent PGs to the inflammatory injury in liver has not been properly addressed [1, 14]. To gain insight into the role of PGs in acute and chronic liver diseases, we have developed a transgenic mouse that expresses human COX-2 constitutively in hepatocytes under the control of the human ApoE promoter. These mice exhibited a normal phenotype but they were resistant to Fas-mediated apoptosis [15]. Although it is widely accepted that PGs contribute to the pathology of various inflammatory diseases, which provide the rational for the development of COX selective inhibitors [16], different reports suggest that $\mathrm{PGE}_{2}$ plays a protective role in various animal models of liver injury [17]. Based on these data, we sought to examine the response of the COX-2-Tg mice in two well established models of inflammatory liver injury: LPS-injury in D-GalN preconditioned mice, an experimental model for fulminant hepatitis in sepsis, and the hepatitis induced 
by intravenous injection of ConA, a model relevant to autoimmune hepatitis. Our data clearly show that $\mathrm{PGE}_{2}$ produced by $\mathrm{COX}-2$ in hepatocytes enhances the levels of anti-apoptotic proteins, decreases the susceptibility to apoptosis after LPS/D-GalN challenge; attenuates the T-cell dependent hepatitis in response to ConA administration, and accelerates the expression of proteins that are involved in the proliferation of hepatocytes in regenerating liver after $\mathrm{PH}$.

\section{MATERIAL AND METHODS}

\section{Chemicals}

Antibodies were from Santa Cruz Laboratories (Santa Cruz, CA), Becton \& Dickinson (New Jersey, NY) and Cell Signaling (Boston, MA). 5, 5-Dimethyl-3(3-fluorophenyl)4-(4-methylsulphonyl) phenyl-2(5H)-furanone (DFU) was from Merck (Rahway, NJ). Reagents were from Roche Diagnostics (Mannheim, Germany) or Sigma Chemical Co. (St. Louis, MO). LPS (from Salmonella Thyphimurium), D-GalN and ConA were obtained from Sigma. Fluorescent probes were from Molecular Probes (Eugene, OR, USA) and Calbiochem (Merck KGaA, Darmstadt, Germany). Akt inhibitor II was from Merck (UK). Reagents for electrophoresis were obtained from Bio-Rad (Hercules, CA).

\section{Liver injury and regeneration models}

To generate mice expressing a human COX-2-Tg in the liver, we used a pLiv-Le6 vector that contains the constitutive human ApoE gene promoter and its hepatic control region [15]. 12 weeks-old $\mathrm{Tg}$ animals (C57BL/6JxDBA) and its corresponding wild type (Wt) littermates were injected intraperitoneally (i.p.) with $1 \mathrm{~g} / \mathrm{kg}$ D-GalN plus 35 $\mu \mathrm{g} / \mathrm{kg}$ LPS. ConA was intravenous (i.v.) injected through the tail vein at a dose of 20 $\mathrm{mg} / \mathrm{kg}$. Untreated animals received $0.5 \mathrm{ml}$ of $\mathrm{NaCl} 0.9 \%$. For $\mathrm{PH}$, mice were anesthetized with a $92: 7 \mathrm{mg} / \mathrm{kg}$ mix of ketamine/xylacine and subjected to midventral laparotomy with $70 \%$ liver resection (left lower and upper and right upper lobes) as described [7]. In some experiments, mice were treated daily for four days with DFU (1 $\mathrm{mg} / \mathrm{kg}$ ) to inhibit COX-2 [18]. Plasma was obtained by puncture of the retro-orbital vein plexus. Animals were sacrificed at six or eight h after LPS/D-GalN or ConA treatment, respectively. Livers were rapidly removed and freeze-clamped in liquid $\mathrm{N}_{2}$ or collected in a solution containing 30\% sucrose in PBS. Animals were treated according to the Institutional Care Instructions. 


\section{Cytokine analysis}

The plasma levels of IFN- $\gamma$, TNF- $\alpha$, IL-1 and IL- 6 were measured by fluorimetry using Bio-Plex Suspension Array System (Cytokine Assay) according to the manufacturer's instructions (Bio-Rad).

\section{Determination of metabolites}

$\mathrm{PGE}_{2}$ was determined in liver tissue by specific immunoassay (Amersham). Briefly, liver samples were homogenized in $0.1 \mathrm{M}$ phosphate buffer $\mathrm{pH} 7.5$, containing $0.9 \%$ BSA and $0.5 \%$ Kathon (assay buffer). After centrifugation, the PGs were analyzed according to manufacturer's instructions. Amino transferases, ALT and ASP, alkaline phosphatase, ALP, and lactate dehydrogenase, LDH, were assayed spectrophotometrically in plasma in the School of Clinic Biochemistry, Faculty of Pharmacy, Complutense University, Madrid, Spain. Protein levels were determined with the Bradford reagent (Bio-Rad).

\section{Histochemistry and immunofluorescence}

Samples of liver were fixed in $10 \%$ buffered formalin, embedded in paraffin wax, sectioned at $3 \mu \mathrm{m}$ and stained with hematoxylin and eosin (H\&E). Histopathology analysis was carried out by the Department of Medicine and Animal Surgery from Faculty of Veterinary, Madrid, Spain. For immunofluorescence analysis, liver samples from $30 \%$ sucrose solution in PBS, were snap-frozen in 2-methylbutane immersed in liquid $\mathrm{N}_{2}$, and serial $8 \mu \mathrm{m}$-thick sections were cut onto gelatinized glass with a Microm HM550 sledge cryostat [15]. The preparations were fixed with 4\% paraformaldehyde $\mathrm{pH} 7$ for $30 \mathrm{~min}$ at room temperature (RT), washed with PBS and permeabilized with methanol for $15 \mathrm{~min}$ at RT. For the detection and quantification of apoptosis, the TUNEL commercial kit for cell death detection (Roche) was used following the instructions of the manufacturer. TO-PRO-3 (Molecular Probes) was used for DNA staining.

\section{Western blot analysis}

Tissue samples (100 mg) were homogenized in a lysis buffer as described [15]. For Western blot analysis, extracts were boiled for $5 \mathrm{~min}$ in Laemmli sample buffer, and equal amounts of protein $(50-70 \mu \mathrm{g})$ were separated by $10-15 \%$ SDS-PAGE. The relative amounts of each protein were determined in total extracts with the following polyclonal or monoclonal antibodies: COX-2, COX-1 and PGES (cytosolic and membrane) (Cayman and Santa Cruz), inhibitors of apoptosis (xIAP) (B \& D Systems), Bcl-2 family proteins (Santa Cruz and Abcam), TNFR pathway (Santa Cruz and Cell 
Signaling), cell cycle proteins, cyclin E, D1, PCNA (Santa Cruz), Akt, and p-Akt (Ser 473), AMPK $\alpha$ and p-AMPKa (Thr172) (Cell Signaling). After incubation with the corresponding anti-rabbit or anti-mouse horseradish peroxidase conjugated secondary antibody, blots were developed by the ECL protocol (Amersham). Target protein band densities were normalized with p85. The blots were revealed, and different exposition times were performed for each blot with a charged coupling device camera in a luminescent image analyzer (Gel-Doc, Bio-Rad).

\section{Caspase assays.}

Livers were homogenized in $20 \mathrm{mM}$ HEPES pH 7.5; $2 \mathrm{mM}$ DTT and 10\% glycerol. The extracts were centrifuged at $8000 \mathrm{~g}$ for $15 \mathrm{~min}$ at $4^{\circ} \mathrm{C}$ and $0.5 \mathrm{mg} / \mathrm{ml}$ of protein supernatant was used to measure caspase activities by cleavage of specific fluorogenic substrates in accordance with the supplier's instructions (BD PharMingen). Substrates were N-acetyl-DEVD-7-amino-4-trifluoromethylcoumarin for caspase 3 and N-acetylIETD-7-amino-4-trifluoromethylcoumarin for caspase 8 . The linearity of caspase assays was determined over a $30 \mathrm{~min}$ reaction period.

\section{Data analysis}

Data are expressed as means \pm standard deviation (SD). Statistical significance of differences between the control and transgenic groups was evaluated by the $U$ of Mann-Whitney test. All tests have been calculated two-tail, and the significance has been considered at $P<0.05$.

\section{RESULTS}

\section{Expression of h-COX-2 and PGE 2 levels in Tg mice after LPS/D-GalN treatment.}

To achieve selective expression of COX-2 in hepatocytes, we generated transgenic (Tg) mice carrying the human isoform of COX-2 (h-COX-2) under the control of the human ApoE promoter and its endogenous hepatic control region [15]. The levels of h-COX-2, COX-1 and microsomal PGE synthase, which catalyzes the isomerization of $\mathrm{PGH}_{2}$ to $\mathrm{PGE}_{2}$, were analyzed in liver extracts from $\mathrm{Wt}$ and $\mathrm{Tg}$ mice after LPS/D-GalN administration. As shown in Fig. 1A, h-COX-2 was significantly expressed in Tg animals but was not detectable in the Wt. Total COX-2 (human and endogenous) was also increased in Tg mice. Low levels of mPGES-1, which preferently couples with COX-2 activity to increase the production of $\mathrm{PGE}_{2}$, and $\mathrm{COX}-1$ were present in Wt and Tg mice and did not change after treatment with LPS/D-GalN. The protein levels of cPGES were higher than those of mPGES-1 and did not change after 
the injury (Fig. 1A); mPGES-2 levels were negligible (not shown). Treatment of the animals with the COX-2 selective inhibitor DFU reduced ( $>75 \%$ ) the $\mathrm{PGE}_{2}$ synthesis (Fig. 1B).

Inhibition of pro-inflammatory cytokines and liver injury in COX-2-Tg mice after LPS/D-GalN treatment.

LPS/D-GalN administration represents an experimental model of fulminant hepatitis in sepsis. LPS is one of the most potent TNF- $\alpha$ inducers, but normally LPS or TNF- $\alpha$ do not cause liver apoptosis unless coadministered with D-GalN which blocks transcription in the liver. To analyze the effect of PG synthesis on LPS/D-GalNdependent injury, the levels of the pro-inflammatory cytokines TNF- $\alpha$, IL-1 and IL-6 were determined. As Fig. 2A shows, a significant increase of circulating cytokine levels was observed in Wt mice by the effect of the injury, but this was much lower, about $50 \%$, in COX-2-Tg mice. When COX-2-Tg mice were treated with DFU, cytokine levels resembled those of the Wt animals. The activities of hepatic injury markers AST, ALT, ALP and LDH were analyzed after $6 \mathrm{~h}$ of LPS/D-GalN administration. After hepatic injury, the increase in plasma levels of aminotransferases observed in COX-2-Tg mice was much lower than in the Wt (> 80\%). When COX-2 was inhibited by treatment with DFU, the protection in the Tg animals was lost (Table I). A representative histological analysis of liver sections of $\mathrm{Wt}$ and $\mathrm{Tg}$ mice treated with LPS/D-GalN is shown in Fig. 2B. After $6 \mathrm{~h}$ following LPS/D-GalN administration, the liver from Wt mice exhibited an important focal necrosis of hepatocytes. In contrast, no evident lesions were observed in the livers of $\mathrm{Tg}$ mice. When $\mathrm{Tg}$ animals were treated with DFU, necrosis and a focal mild hepatitis were observed resembling the Wt liver. To determine the contribution of apoptosis to liver injury, TUNEL of histological liver sections and measurement of the caspase 3 and 8 activities were carried out. As shown in Fig. 2C, a significant decrease in TUNEL staining was observed in Tg animals compared with Wt. Moreover, when Tg animals were treated with DFU, again TUNEL increased after LPS/D-GalN administration. The activity and protein levels of the active form of caspase 3 were markedly lower in Tg liver after LPS/D-GalN treatment than in Wt counterparts (40\% and 30\% for caspase 3 and 8, respectively; Fig. 4A-B). 


\section{COX-2 dependent PGs prevent liver injury induced by ConA.}

ConA induced liver injury is mediated by the activation of the innate and adaptive immune cells including natural killer cells (NK), Kupffer cells and CD4 ${ }^{+} \mathrm{T}$ cells and their production of inflammatory cytokines, such as IL-6, IL-2, TNF- $\alpha$ and IFN- $\gamma$ [19]. Tg animals expressing COX-2 in liver exhibited a significant decrease of ConA-induced injury, mainly in IFN- $\gamma$, IL-1 and IL-6 levels (Fig. 3A), as well as on liver injury markers (Table II). Histological analysis of liver sections of Wt and $\mathrm{Tg}$ mice treated with ConA is shown in Fig. 3B. Livers from Wt mice exhibited focal mild areas of necrosis in hepatocytes whereas no remarkable lesions were observed in $\mathrm{Tg}$ mice. Caspase 3-like activity was minimally induced in both Wt and $\mathrm{Tg}$ mice by the effect of ConA (note the difference of magnitude vs. the LPS/D-GalN model), and a minimal processing of procaspase 3 was observed in the Wt mice (Fig. 4C-D).

\section{Altered expression of apoptotic related proteins after liver injury in h-COX-2 Tg mice.}

To address the anti-apoptotic mechanism of COX-2 acting upon LPS/D-GalN or ConA mediated liver injury, we investigated the expression of apoptosis-related proteins. As Fig. 5A shows, the protein levels of TNFR1, TRADD and XIAP were equivalent in Wt and Tg mice and no differences were found after treatments. Bax was increased in Wt mice after injury and no changes were observed in Tg mice. Bcl-2 and Mcl-1 levels were increased in Tg liver under basal conditions and were maintained after LPS/D-GalN treatment. TNFR2 and TRAF2 (TNF receptor-associated factor 2) decreased by the effect of the treatment in Wt but not in COX-2 expressing liver, indicating an increased sensitivity to TNF-induced apoptosis in Wt mice. Moreover, an increase in the $\mathrm{Bcl}-2 / \mathrm{Bax}(170 \%)$ ratio was observed in $\mathrm{Tg}$ mice after LPS/D-GalN treatment (Fig. 5C). Similar results were obtained when all these parameters were measured in Wt and Tg mice treated with ConA (Fig. 5B-D).

The PI3K/Akt and AMPK pathways play a central role in integrating diverse survival signals. An increase in the p-Akt/Akt ( $>3$ fold) and more moderate in the p-AMPK $\alpha / A M P K \alpha$ (1.5 fold) ratio were observed in Tg mice after LPS/D-GalN (Fig. 6A) or ConA injury (Fig. 6B). To confirm the contribution of PGs synthesis on Akt phosphorylation, we performed experiments in liver cell lines with stable expression of COX-2 as described previously [20]. A significant inhibition of the apoptosis induced by the effect of LPS/D-GalN in CHL-C cells (cells transfected with COX-2) comparing with the CHL-V cells (cells transfected with empty vector) was observed. Moreover, 
when cells were treated with the specific Akt inhibitor II, the number of apoptotic CHL-C cells was doubled indicating that Akt activation plays an important role in the inhibition of apoptosis promoted by PGs (Fig. 6C). To know the contribution of PGs to AMPK activation, CHL-C and CHL-V cells were treated with LPS/D-GalN and, as shown in Fig. 6D, AMPK was phosphorylated under basal conditions in agreement with the in vivo results (Fig. 6A). When CHL-V cells were treated with LPS/D-GalN, AMPK activation decreased; however, CHL-C or CHL-V cells treated with $\mathrm{PGE}_{2}$, maintained the phosphorylation state of AMPK. DFU treatment reversed theses effects.

To gain further insight into this differential response to liver injury in Wt and COX-2-Tg mice, we used a specific mouse apoptosis micro array to compare the expression profile after treatment with LPS/D-GalN. Fig. 7A summarizes both the magnitude of changes and the corresponding statistical significance of the 84 apoptosisrelated genes analyzed. We sorted the candidate genes whose expression threshold after LPS/D-GalN treatment was altered more than 2-fold (Fig. 7B). As we expected from the previous results, the majority of the up-regulated genes in Wt treated mice were proapoptotic (Apaf1, Casp1, Casp14, Casp4, Fasl, Tnf, Tnfsf10, Trp63, Trp73) and the down-regulated genes were anti-apoptotic (Api5, Bag3, Birc5, Dapk1, Mcl1, Sphk2, Traf2, Zc3Hc1). However, Tg mice exhibited opposite and attenuated changes of these genes (Api, Bag1, Bax, Plob, Traf2).

\section{COX-2 Tg mice exhibit an accelerated hepatocyte proliferation after $\mathrm{PH}$.}

Because liver regeneration after PH implies a negligible apoptosis under normal conditions, we decided to evaluate the effect of the COX-2 Tg after PH. As previously described [7], COX-2 protein levels increased after PH and the levels of COX-1 and mPGES did not change (Fig. 8C). Fig. 8A shows similar survival rates for Wt and Tg mice after $\mathrm{PH}$ and no significant differences were found in the liver regeneration index at $80 \mathrm{~h}$ after $\mathrm{PH}$ (Fig. 8B). When cell cycle proteins were analyzed, significant differences were found in the levels of proliferating cell nuclear antigen (PCNA), cyclin D1 and cyclin $\mathrm{E}$ between $\mathrm{Tg}$ and the corresponding Wt mice. As shown in Fig. 8D-E, cyclin D1 was present in Tg mice at $0 \mathrm{~h}$, increased at $12 \mathrm{~h}$ and remained elevated at $24 \mathrm{~h}$ after $\mathrm{PH}$; cyclin E increased at $12 \mathrm{~h}$ and the raise of PCNA after PH was evidenced at 48 and $96 \mathrm{~h}$. 


\section{DISCUSSION}

We have studied the effect of constitutive expression of COX-2 in the hepatocyte on the liver response to three distinct insults: LPS/D-GalN, ConA and PH. These Tg animals exhibited higher levels of some anti-apoptotic genes of the Bcl-2 family and were significantly resistant to LPS/D-GalN-induced injury, mainly through an inhibition of the apoptotic response characteristic of this model. It has been reported that D-GalN co-administered with LPS, represents an experimental model for fulminant hepatitis in sepsis due to massive hepatocyte apoptosis, mainly caused by an abrupt TNF- $\alpha$ rise in the absence of transcription [21]. Under these conditions, COX-2 Tg animals exhibited a much lesser pro-inflammatory profile than the corresponding $\mathrm{Wt}$ animals. TNF- $\alpha$ signals through two distinct membrane receptors: TNFR1 and TNFR2. TNFR1, but not TNFR2 can directly activate the caspase 8 apoptotic pathway through its cytoplasmic death domain (DD) [22]. Through TRADD, TNFR1 engagement also leads to IKK and JNK activation. While IKK activation has a clear antiapoptotic function, different results have been reported for the role of JNK activation in TNF- $\alpha$-induced apoptosis [23]. Our data show a decrease in TNFR2 by the effect of LPS/D-GalN treatment in Wt mice and this may be due to a down-regulation of the receptor described during endotoxemia [24]. Although TNFR2 lacks a death domain, it has also been associated with the apoptotic response to TNF- $\alpha$. It is known that TNFR2 triggering induces degradation and depletion of TRAF2 and IAP proteins and accelerates TNFR1-dependent activation of caspase 8 [25]. TRAF2 protein levels were depleted by the effect of the injury in Wt mice but not in the COX-2-Tg liver supporting the hypothesis that TRAF2 provides anti-apoptotic signals following TNF-stimulation.

Intravenous administration of ConA is an excellent model resembling immunemediated fulminant hepatic failure in humans. As reported [26], ConA rapidly induced $(6-24 \mathrm{~h})$ clinical and histological evidenced of hepatitis, including elevation of transaminases, $\mathrm{T}$ cell infiltration and necrosis. ConA-induced liver injury is mediated by the activation of the innate and adaptive immune cells including NKs, Kupffer cells and $\mathrm{CD}^{+} \mathrm{T}$ cells and their production of inflammatory cytokines, such as TNF- $\alpha$ and IFN $-\gamma$. IFN- $\gamma$ plays a critical role in $\mathrm{T}$ cell-dependent liver injury initiated by ConA since IFN- $\gamma$ KO mice are protected from hepatic injury [27]. In agreement with this mechanism, treatment with ConA produced a rise in IFN- $\gamma$ levels, an effect that was markedly reduced in COX-2 $\mathrm{Tg}$ mice, which suggests that PGs are interfering on immune cell activation, in particular lymphocytes. In this regard, it should be mentioned 
that previous work described an inhibitory effect by PGs on T cell activation [28]. The activation of caspase 3 observed in ConA-treated mice was less than $80 \%$ of that observed after LPS/D-GalN challenge and, indeed, a negligible procaspase 3 processing to caspase 3 was observed in ConA treated animals in our conditions, suggesting that ConA is mainly promoting a cytolytic/necrotic response in agreement with the rapid rise in plasma levels of transaminases. Although in both liver injury models the expression of the COX-2 Tg exerted a very important protection, it is noteworthy mention that the cellular and molecular mechanisms underlying this effect appear to be different: protection against apoptosis in the LPS/D-GalN model, and attenuation of the immunecell dependent hepatocyte necrosis in the case of ConA administration.

The pro-inflammatory and cytoprotective functions of COX-2 in liver remain unclear, mainly because hepatocytes, but not other hepatic cells, fail to express COX-2 upon pro-inflammatory challenge [29]. It has been reported that expression of a COX-2 $\mathrm{Tg}$ causes hepatitis in senescent animals [30]; however, different reports demonstrated that $\mathrm{PGE}_{2}$ administration protects against liver injury after E. coli infection by suppressing circulating TNF- $\alpha$ and IL-12 levels and increasing IL-10 production [31]. The $\mathrm{PGE}_{2}$-EP4 signalling pathway effectively protects against hepatic ischemia/reperfusion injury because EP4 agonists downregulated the expression of several pro-inflammatory cytokines, chemokines and adhesion molecules [17]. $\mathrm{PGE}_{2}$ downregulates Kupffer cell production of IL-1 and IL-6 during hepatic regeneration and LPS liver injury [32] and attenuates the acute phase response through a decrease in IL-6-induced $\alpha$-2 macroglobulin formation via a cAMP-dependent signalling [33]. Our results agree with these data and show that COX-2-dependent PGs cause an important decrease in the plasma levels of pro-inflammatory cytokines and a significant improvement in liver function after LPS/D-GalN or ConA challenge compared with the Wt counterparts. In this regard, Yin et al. [34] by using COX $-2^{-/-}$mice demonstrated an increased susceptibility of COX $-2^{-/-}$mice to ConA-induced hepatitis.

Studies with different $\mathrm{Tg}$ mouse models of $\mathrm{COX}-2$ also demonstrated the important anti-apoptotic role for PGs. Tg mice expressing COX-2 in mammary gland developed tumours, and these animals had reduced levels of the proapoptotic proteins Bax and Bcl- $\mathrm{x}_{\mathrm{S}}$ and elevated levels of the antiapoptotic protein Bcl-2 [35]. A different study demonstrated hyperplasic gastric tumours in Tg mice expressing COX-2 and mPGES. This study relates $\mathrm{PGE}_{2}$ with the recruitment, infiltration and activation of mucosal macrophages establishing a relationship between inflammation and tumour cell 
growth [36]. Our previous results obtained with stable expression of COX-2 in liver cell lines and with mouse hydrodynamically transfected with a COX-2-GFP expression vector, supported the view that PGs produced by COX-2 protected the liver against Fas-mediated apoptosis [20]. In this work we show that PGs produced by COX-2 in liver, increased the levels of Bcl-2, Mcl-1, TNFR2 and TRAF2, all these hallmarks of apoptotic/anti-apoptotic pathway, and were confirmed by a PCR array analysis specific for apoptosis profile. Several signalling pathways have been proposed as mediators of COX-2-dependent inhibition of apoptosis; however, few reports describe the direct effect of COX-2 expression on apoptosis in liver or HCC cells. Leng et al.[37] reported an enhanced phosphorylation of Akt in Hep3B cells transiently or permanently transfected with a COX-2 expression vector; overexpression of COX-2 in rat intestinal epithelial cells increased their resistance to undergo apoptosis and resulted in increased Bcl-2 protein levels [38] and COX-2 induces a Mcl-1-dependent survival mechanism in human lung adenocarcinoma cells [39]. Targets of PGs through their EP receptors are the PI3K and the Akt/PKB pathways. The PI3K/Akt is important in modulating the mammalian target of rapamycin, which acts as a central sensor for nutrient/energy availability, thereby regulating cell growth. Activation of Akt and Ga subunit of EP receptors can also result in the accumulation of $\beta$-catenin of the canonical Wnt pathway in the nucleus, which also leads to transcriptional activation [40]. Akt improves cellular energy stores by accelerating cell proliferation and size, while induces antiapoptotic effects by phosphorylation and inactivation of the proapoptotic protein $\mathrm{Bad}$, and by the upregulation of Bcl-2 and $\mathrm{Mcl}-1$ [41]. Our results show that in the liver of COX-2-Tg mice, both Akt and AMP-kinase are phosphorylated indicating a reinforcement of survival pathways and a higher efficiency in energetic metabolism, preventing ATP depletion [42]. These circumstances concur in favouring liver protection after acute injury.

It has been described $[7,43]$ that PGs produced by COX-2 are important for the early steps of liver regeneration after $\mathrm{PH}$. Because liver regeneration after $\mathrm{PH}$ is characterized by a negligible concurrence of apoptosis, we investigated whether the COX-2 Tg might influence the hepatocyte proliferation. Our results show that PGs anticipated the initial cell cycle progression without noticeable changes in the rate of mass recovery at the end (5-days) of the regeneration process. As potential mechanisms responsible for this rapid cell commitment for proliferation, it is known that PGs increase cyclin D1 levels through $\beta$-catenin pathway [44], and that both AMPK and Akt 
facilitate cell entry into the cell cycle [45], and these enzymes are 'more active' in the COX-2-Tg mice. It is relevant to note that continuous generation of $\mathrm{PGE}_{2}$ in the hepatocytes contributes to higher levels of cyclins and a more intense expression of PCNA. However, these circumstances did not contribute to acceleration in the regeneration process, suggesting that rate-limiting factors play a role after $\mathrm{PH}$ and provide a fine kinetic control for hepatocyte proliferation.

Finally, although these studies have been performed using acute liver injury approaches and showed tissue protection, further studies with this COX-2-Tg mice, might help to elucidate whether this COX-2 expression protects or might sensitize mouse liver for chronic diseases and carcinogenesis.

Acknowledgement: The authors wish to thanks Alfonso Moyano for technical assistance. 


\section{REFERENCES}

1 Avila, M. A., Berasain, C., Sangro, B. and Prieto, J. (2006) New therapies for hepatocellular carcinoma. Oncogene. 25, 3866-3884

2 Simmons, D. L., Botting, R. M. and Hla, T. (2004) Cyclooxygenase isozymes: the biology of prostaglandin synthesis and inhibition. Pharmacol. Rev. 56, 387-437

3 Pilbeam, C. C., Kawaguchi, H., Hakeda, Y., Voznesensky, O., Alander, C. B. and Raisz, L. G. (1993) Differential regulation of inducible and constitutive prostaglandin endoperoxide synthase in osteoblastic MC3T3-E1 cells. J. Biol. Chem. 268, 25643-25649

4 Feng, L., Xia, Y., Garcia, G. E., Hwang, D. and Wilson, C. B. (1995) Involvement of reactive oxygen intermediates in cyclooxygenase-2 expression induced by interleukin-1, tumor necrosis factor-alpha, and lipopolysaccharide. J. Clin. Invest. 95, 1669-1675

5 Martin-Sanz, P., Callejas, N. A., Casado, M., Diaz-Guerra, M. J. and Bosca, L. (1998) Expression of cyclooxygenase-2 in foetal rat hepatocytes stimulated with lipopolysaccharide and pro-inflammatory cytokines. Br. J. Pharmacol. 125, 13131319

6 Ledwith, B. J., Pauley, C. J., Wagner, L. K., Rokos, C. L., Alberts, D. W. and Manam, S. (1997) Induction of cyclooxygenase-2 expression by peroxisome proliferators and non-tetradecanoylphorbol 12,13-myristate-type tumor promoters in immortalized mouse liver cells. J. Biol. Chem. 272, 3707-3714

7 Casado, M., Callejas, N. A., Rodrigo, J., Zhao, X., Dey, S. K., Bosca, L. and MartinSanz, P. (2001) Contribution of cyclooxygenase 2 to liver regeneration after partial hepatectomy. FASEB J. 15, 2016-2018

8 Fernandez-Martinez, A., Callejas, N. A., Casado, M., Bosca, L. and Martin-Sanz, P. (2004) Thioacetamide-induced liver regeneration involves the expression of cyclooxygenase 2 and nitric oxide synthase 2 in hepatocytes. J. Hepatol. 40, 963-970

9 Yamamoto, H., Kondo, M., Nakamori, S., Nagano, H., Wakasa, K., Sugita, Y., Chang-De, J., Kobayashi, S., Damdinsuren, B., Dono, K., Umeshita, K., Sekimoto, M., Sakon, M., Matsuura, N. and Monden, M. (2003) JTE-522, a cyclooxygenase-2 inhibitor, is an effective chemopreventive agent against rat experimental liver fibrosis1. Gastroenterology. 125, 556-571

10 Lara-Pezzi, E., Gomez-Gaviro, M. V., Galvez, B. G., Mira, E., Iniguez, M. A., Fresno, M., Martinez, A. C., Arroyo, A. G. and Lopez-Cabrera, M. (2002) The hepatitis $\mathrm{B}$ virus $\mathrm{X}$ protein promotes tumor cell invasion by inducing membrane-type matrix metalloproteinase- 1 and cyclooxygenase-2 expression. J. Clin. Invest. 110, 1831-1838

11 Nunez, O., Fernandez-Martinez, A., Majano, P. L., Apolinario, A., Gomez-Gonzalo, M., Benedicto, I., Lopez-Cabrera, M., Bosca, L., Clemente, G., Garcia-Monzon, C. and Martin-Sanz, P. (2004) Increased intrahepatic cyclooxygenase 2, matrix metalloproteinase 2, and matrix metalloproteinase 9 expression is associated with progressive liver disease in chronic hepatitis $\mathrm{C}$ virus infection: role of viral core and NS5A proteins. Gut. 53, 1665-1672

12 Kern, M. A., Schubert, D., Sahi, D., Schoneweiss, M. M., Moll, I., Haugg, A. M., Dienes, H. P., Breuhahn, K. and Schirmacher, P. (2002) Proapoptotic and antiproliferative potential of selective cyclooxygenase-2 inhibitors in human liver tumor cells. Hepatology. 36, 885-894

13 Morinaga, S., Yamamoto, Y., Noguchi, Y., Imada, T., Rino, Y., Akaike, M., Sugimasa, Y., Takemiya, S., Kameda, Y. and Takanashi, Y. (2002) Cyclooxygenase- 
2 mRNA is up-regulated in cirrhotic or chronic hepatitis liver adjacent to hepatocellular carcinoma. J. Gastroenterol. Hepatol. 17, 1110-1116

14 Canbay, A., Friedman, S. and Gores, G. J. (2004) Apoptosis: the nexus of liver injury and fibrosis. Hepatology. 39, 273-278

15 Casado, M., Molla, B., Roy, R., Fernandez-Martinez, A., Cucarella, C., Mayoral, R., Bosca, L. and Martin-Sanz, P. (2007) Protection against Fas-induced liver apoptosis in transgenic mice expressing cyclooxygenase 2 in hepatocytes. Hepatology. 45, 631638

16 Gilroy, D. W. and Colville-Nash, P. R. (2000) New insights into the role of COX 2 in inflammation. J. Mol. Med. 78, 121-129

17 Kuzumoto, Y., Sho, M., Ikeda, N., Hamada, K., Mizuno, T., Akashi, S., Tsurui, Y., Kashizuka, H., Nomi, T., Kubo, A., Kanehiro, H. and Nakajima, Y. (2005) Significance and therapeutic potential of prostaglandin E2 receptor in hepatic ischemia/reperfusion injury in mice. Hepatology. 42, 608-617

18 Riendeau, D., Percival, M. D., Boyce, S., Brideau, C., Charleson, S., Cromlish, W., Ethier, D., Evans, J., Falgueyret, J. P., Ford-Hutchinson, A. W., Gordon, R., Greig, G., Gresser, M., Guay, J., Kargman, S., Leger, S., Mancini, J. A., O'Neill, G., Ouellet, M., Rodger, I. W., Therien, M., Wang, Z., Webb, J. K., Wong, E., Chan, C. C. and et al. (1997) Biochemical and pharmacological profile of a tetrasubstituted furanone as a highly selective COX-2 inhibitor. Br. J. Pharmacol. 121, 105-117

19 Trautwein, C., Rakemann, T., Brenner, D. A., Streetz, K., Licato, L., Manns, M. P. and Tiegs, G. (1998) Concanavalin A-induced liver cell damage: activation of intracellular pathways triggered by tumor necrosis factor in mice. Gastroenterology. 114, 1035-1045

20 Fernandez-Martinez, A., Molla, B., Mayoral, R., Bosca, L., Casado, M. and MartinSanz, P. (2006) Cyclo-oxygenase 2 expression impairs serum-withdrawal-induced apoptosis in liver cells. Biochem. J. 398, 371-380

21 Nowak, M., Gaines, G. C., Rosenberg, J., Minter, R., Bahjat, F. R., Rectenwald, J., MacKay, S. L., Edwards, C. K., 3rd and Moldawer, L. L. (2000) LPS-induced liver injury in D-galactosamine-sensitized mice requires secreted TNF-alpha and the TNFp55 receptor. Am. J. Physiol. Regul. Integr. Comp. Physiol. 278, R1202-1209

22 Hsu, H., Shu, H. B., Pan, M. G. and Goeddel, D. V. (1996) TRADD-TRAF2 and TRADD-FADD interactions define two distinct TNF receptor 1 signal transduction pathways. Cell. 84, 299-308

23 Maeda, S., Chang, L., Li, Z. W., Luo, J. L., Leffert, H. and Karin, M. (2003) IKKbeta is required for prevention of apoptosis mediated by cell-bound but not by circulating TNFalpha. Immunity. 19, 725-737

24 van der Poll, T., Coyle, S. M., Kumar, A., Barbosa, K., Agosti, J. M. and Lowry, S. F. (1997) Down-regulation of surface receptors for TNF and IL-1 on circulating monocytes and granulocytes during human endotoxemia: effect of neutralization of endotoxin-induced TNF activity by infusion of a recombinant dimeric TNF receptor. J. Immunol. 158, 1490-1497

$25 \mathrm{Li}, \mathrm{X}$., Yang, Y. and Ashwell, J. D. (2002) TNF-RII and c-IAP1 mediate ubiquitination and degradation of TRAF2. Nature. 416, 345-347

26 Tiegs, G., Hentschel, J. and Wendel, A. (1992) A T cell-dependent experimental liver injury in mice inducible by concanavalin A. J. Clin. Invest. 90, 196-203

27 Hong, F., Jaruga, B., Kim, W. H., Radaeva, S., El-Assal, O. N., Tian, Z., Nguyen, V. A. and Gao, B. (2002) Opposing roles of STAT1 and STAT3 in T cell-mediated hepatitis: regulation by SOCS. J. Clin. Invest. 110, 1503-1513 
28 Kim, R., Emi, M., Tanabe, K. and Arihiro, K. (2006) Tumor-driven evolution of immunosuppressive networks during malignant progression. Cancer Res. 66, 55275536

29 Callejas, N. A., Bosca, L., Williams, C. S., Du, B. R. and Martin-Sanz, P. (2000) Regulation of cyclooxygenase 2 expression in hepatocytes by CCAAT/enhancerbinding proteins. Gastroenterology. 119, 493-501

30 Yu, J., Hui, A. Y., Chu, E. S., Cheng, A. S., Go, M. Y., Chan, H. L., Leung, W. K., Cheung, K. F., Ching, A. K., Chui, Y. L., Chan, K. K. and Sung, J. J. (2007) Expression of a cyclo-oxygenase-2 transgene in murine liver causes hepatitis. Gut. 56, 991-999

31 Takano, M., Nishimura, H., Kimura, Y., Washizu, J., Mokuno, Y., Nimura, Y. and Yoshikai, Y. (1998) Prostaglandin E2 protects against liver injury after Escherichia coli infection but hampers the resolution of the infection in mice. J. Immunol. 161, 3019-3025

32 Treffkorn, L., Scheibe, R., Maruyama, T. and Dieter, P. (2004) PGE2 exerts its effect on the LPS-induced release of TNF-alpha, ET-1, IL-1alpha, IL-6 and IL-10 via the EP2 and EP4 receptor in rat liver macrophages. Prostaglandins Other Lipid Mediat. 74, 113-123

33 Fennekohl, A., Lucas, M. and Puschel, G. P. (2000) Induction by interleukin 6 of $\mathrm{G}(\mathrm{s})$-coupled prostaglandin $\mathrm{E}(2)$ receptors in rat hepatocytes mediating a prostaglandin $\mathrm{E}(2)$-dependent inhibition of the hepatocyte's acute phase response. Hepatology. 31, 1128-1134

34 Yin, H., Cheng, L., Langenbach, R. and Ju, C. (2007) Prostaglandin I(2) and E(2) mediate the protective effects of cyclooxygenase- 2 in a mouse model of immunemediated liver injury. Hepatology. 45, 159-169

35 Liu, C. H., Chang, S. H., Narko, K., Trifan, O. C., Wu, M. T., Smith, E., Haudenschild, C., Lane, T. F. and Hla, T. (2001) Overexpression of cyclooxygenase2 is sufficient to induce tumorigenesis in transgenic mice. J. Biol. Chem. 276, 1856318569

36 Oshima, H., Oshima, M., Inaba, K. and Taketo, M. M. (2004) Hyperplastic gastric tumors induced by activated macrophages in COX-2/mPGES-1 transgenic mice. EMBO J. 23, 1669-1678

37 Leng, J., Han, C., Demetris, A. J., Michalopoulos, G. K. and Wu, T. (2003) Cyclooxygenase-2 promotes hepatocellular carcinoma cell growth through Akt activation: evidence for Akt inhibition in celecoxib-induced apoptosis. Hepatology. 38, 756-768

38 Tsujii, M. and DuBois, R. N. (1995) Alterations in cellular adhesion and apoptosis in epithelial cells overexpressing prostaglandin endoperoxide synthase 2. Cell. 83, 493501

39 Lin, M. T., Lee, R. C., Yang, P. C., Ho, F. M. and Kuo, M. L. (2001) Cyclooxygenase-2 inducing Mcl-1-dependent survival mechanism in human lung adenocarcinoma CL1.0 cells. Involvement of phosphatidylinositol 3-kinase/Akt pathway. J. Biol. Chem. 276, 48997-49002

40 Buchanan, F. G. and DuBois, R. N. (2006) Connecting COX-2 and Wnt in cancer. Cancer Cell. 9, 6-8

41 Schulze-Bergkamen, H., Brenner, D., Krueger, A., Suess, D., Fas, S. C., Frey, C. R., Dax, A., Zink, D., Buchler, P., Muller, M. and Krammer, P. H. (2004) Hepatocyte growth factor induces Mcl-1 in primary human hepatocytes and inhibits CD95mediated apoptosis via Akt. Hepatology. 39, 645-654 
42 Havel, P. J. (2004) Update on adipocyte hormones: regulation of energy balance and carbohydrate/lipid metabolism. Diabetes. 53 Suppl 1, S143-151

43 Rudnick, D. A., Perlmutter, D. H. and Muglia, L. J. (2001) Prostaglandins are required for CREB activation and cellular proliferation during liver regeneration. Proc. Natl. Acad. Sci. U S A. 98, 8885-8890

44 Shao, J., Jung, C., Liu, C. and Sheng, H. (2005) Prostaglandin E2 Stimulates the beta-catenin/T cell factor-dependent transcription in colon cancer. J. Biol. Chem. 280, 26565-26572

45 Amaravadi, R. and Thompson, C. B. (2005) The survival kinases Akt and Pim as potential pharmacological targets. J. Clin. Invest. 115, 2618-2624

\section{FIGURE LEGENDS}

Figure 1. Expression of human COX-2 in Tg mice after LPS/D-GalN treatment. (A) Human and total COX-2, mPGES-1, cPGES and COX-1 protein expression in liver homogenates from Wt and COX-2-Tg animals with or without LPS/D-GalN treatment (6 hours) detected by Western blot and normalized with p85. Abs were from Cayman and Santa Cruz. (B) Intrahepatic $\mathrm{PGE}_{2}$ concentrations were determined by ELISA in liver homogenates in the presence or absence of $1 \mathrm{mg} / \mathrm{kg}$ of DFU. Data are the means \pm SD of six animals per condition. ${ }^{*} P<0.05 v s$. the corresponding Wt animals treated under identical conditions. ${ }^{\#} P<0.05$ vs. the corresponding $\mathrm{Tg}$ animals treated without DFU.

Figure 2. Inhibition of pro-inflammatory cytokines and liver injury in COX-2-Tg mice after LPS/D-GalN treatment. (A) TNF- $\alpha$, IL-1 and IL-6 were measured after $2 \mathrm{~h}$ of treatment in plasma by fluorimetric analysis using Bio-Plex Suspension Array System (Bio-Rad). (B) Hematoxylin and eosin (H\&E) analysis of liver sections of a 12weeks-old Wt and Tg mice after treatment. Figures were taken with a CVD Camera at

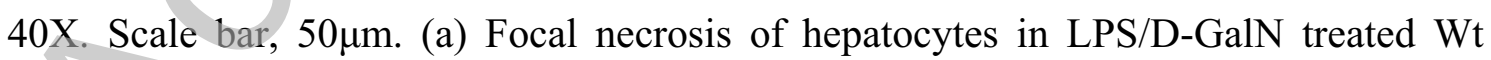
mice. (b) No lesions were observed in the liver of TG mice under the same conditions. (c-d) Diffuse moderate acute and focal mild hepatitis is observed in Wt and Tg mice treated with DFU respectively. (C) Apoptosis in liver sections taken 6 hours after injection with LPS/D-GalN. Confocal images were obtained with a Leica TCS SP2 Spectral microscope and a 63x/1.40 NA oil objective (Leica Microsystems, Wetzlar, 
Germany). A representative result of TUNEL analysis (red fluorescence) and nuclear staining with TO-PRO-3 (blue). Scale bar, $40 \mu \mathrm{m}$. Original magnification, 63X. The percentage of apoptotic cells was quantified and results show the mean \pm SD of five sections per animal $(\mathrm{n}=4)$. Results are mean $\pm \mathrm{SD}$ of five animals per condition. * $* *$ denotes $P<0.05$ and $P<0.001$ vs. the corresponding Wt mice treated under identical conditions. ${ }^{\#} P<0.05$ vs. the corresponding Tg animals treated without DFU.

Figure 3. COX-2 dependent PGs prevent liver injury induced by ConA. ConA was i.v. at $20 \mathrm{mg} / \mathrm{kg}$ to $\mathrm{Wt}$ and $\mathrm{Tg}$ mice. (A) Plasma levels of cytokines after $2 \mathrm{~h}$ of ConA treatment were measured by fluorimetric analysis using Bio-Plex (Bio-Rad). (B) Histological analysis of liver sections of a 12-weeks-old Wt littermate and Tg mice after ConA treatment and stained with H\&E (40X; scale bar, $50 \mu \mathrm{m}$ ). Mild focal necrosis of hepatocytes in ConA-treated Wt liver whereas no remarkable lesions were observed in the liver of $\mathrm{Tg}$ mice. Results are mean $\pm \mathrm{SD}$ of five animals per condition. *,** denotes $P<0.05$ and $P<0.001$ vs. the corresponding Wt mice treated under identical conditions.

Figure 4. Expression of COX-2 inhibits caspase like activities. Caspase 3 and 8 were measured as DEVDase and IETDase activities in $\mathrm{Wt}$ and $\mathrm{Tg}$ liver homogenates. Caspase activities were measured by fluorimetric assay with specific fluorogenic substrates (see Materials and Methods) after LPS/D-Gal N (A-B) or ConA (C-D) treatment. Note the different scale in the A-C panel. Liver extracts were also used to determine the amount of pro-caspase 3 by Western blot. Blots were normalized for protein content with $\mathrm{p} 85$. Data are the means $\pm \mathrm{SD}$ of five animals per condition. $* P<$ $0.05 v s$. the Wt mice treated under identical conditions.

\section{Figure 5. Altered expression of apoptotic related proteins in COX-2-expressing liver.}

Representative Western blots showing the expression of Bcl- $\mathrm{x}_{\mathrm{L}}, \mathrm{Bcl}-2$, Bax, xIAP, Mcl1, TNFR1, TNFR2, TRAF-2 and TRADD in Wt and Tg animals. Densitometric analysis of the expression of Bcl-2/Bax ratio after LPS/D-GalN (6 h) (A-C) or ConA (8 h) (B-D) treatment. The expression of target proteins was normalized to that of p85 and the ratios are expressed as percentage of the Wt value without treatment. Data are the means $\pm \mathrm{SD}$ of six animals per condition. ${ }^{*}$ denotes $P<0.05 v s$. the Wt mice treated under identical conditions. 
Figure 6. Akt and AMPK activation in COX-2-Tg mice and in liver cell lines. Representative Western blots showing the expression of p-Akt/Akt and pAMPK $\alpha / A M P K \alpha$ in $\mathrm{Wt}$ and Tg animals. Densitometric analysis of the expression of pAkt/Akt after LPS/D-GalN (6 h) (A) or ConA (8 h) (B) treatment. Ab for Akt, and pAkt (Ser 473), AMPK $\alpha$ and p-AMPKa (Thr172) were from Cell Signaling. (C) CHL-C (stable transfected with pcDNA3hCOX-2) and CHL-V (transfected with pcDNA3) cells $\left(50 \times 10^{3}\right)$ were treated with $5 \mathrm{mM}$ D-GalN plus $100 \mathrm{ng} / \mathrm{ml}$ LPS or $5 \mu \mathrm{M}$ Akt inhibitor II for $12 \mathrm{~h}$. After that, cells resuspended in PBS were PI-stained and cell viability was determined in a BD FACS Canto I cell cytometry. (D) CHL-C and CHL-V cells $\left(1 \times 10^{6}\right)$ were preincubated with $5 \mu \mathrm{M} \mathrm{PGE}_{2}$ or $5 \mu \mathrm{M}$ DFU for $1 \mathrm{~h}$ and then treated with $5 \mathrm{mM}$ D-GalN plus $100 \mathrm{ng} / \mathrm{ml}$ LPS for $12 \mathrm{~h}$. Protein levels of p-AMPK $\alpha / A M P K \alpha$ were measured by Western blot and the densitometric analysis is shown. The expression of target proteins was normalized to that of $\mathrm{p} 85$ and the ratios are expressed as percentage of the Wt value without treatment. Data are the means \pm SD of six animals per condition or three independent experiments. ${ }^{*}$, ** denotes $P<0.05$ and $P<0.001$ vs. the Wt mice or the CHL-V cells treated under identical conditions.

Figure 7. Transcriptional profiling of COX-2 expressing liver after LPS/D-GalN treatment. Total RNA was isolated from liver with TRIzol Reagent (Invitrogen, Carlsbad, California, USA) and further cleaned up using the Qiagen RNeasy MiniKit (Hilden, Germany) with one step of DNase I digestion following the manufacturer's instructions. $2 \mu \mathrm{g}$ of RNA were used for cDNA synthesis with $\mathrm{RT}^{2}$ First Standard kit (SuperArray Bioscience, Frederick, MD). The mouse apoptosis PCR array was performed according to the manufacturer's protocol, using the Profiler PCR Array System and the SYBR Green/Fluorescein qPCR master mix (SuperArray Bioscience) on a MyiQ Real-Time PCR System (Bio-Rad). Gene expression was compared with the web-based software package for the PCR Array System (http://www.superarray.com/pcr/arrayanalysis.php); this software automatically performs all $\Delta \Delta C_{t}$ based fold-change calculations from the specific uploaded raw threshold cycle data. (A) Volcano plot shows the $\log 2$ fold change of apoptosis-related genes versus their p-values. Each point represents a plot containing $\log 2$ of the fold change in gene expression threshold for two conditions (saline vs. LPS/D-GalN) on the $x$ axis and the $\mathrm{p}$ value on the $y$ axis. Points over the horizontal blue line indicated the $\mathrm{p}$ - 
value of $<0.01$. (B) Colorimetric diagram with a selection of the 84 apoptosis-related genes analyzed. Genes whose transcription is up/down (red/green) two fold in gene expression threshold after LPS/D-GalN treatment are shown. All data presented are the means of four animals per condition.

\section{Figure 8. COX-2 expressing hepatocytes exhibit an accelerated proliferation after}

$\boldsymbol{P H}$. For $\mathrm{PH}, \mathrm{Wt}$ and $\mathrm{Tg}$ mice were subjected to midventral laparotomy with $70 \%$ liver resection and total extracts were prepared. (A) Survival rates of Wt and COX-2-Tg mice at $120 \mathrm{~h}$ after PH. (B) Liver regeneration index at the indicated times after PH. (C) COX-2, mPGES and COX-1 protein expression in liver homogenates from $\mathrm{Wt}$ and $\mathrm{COX}-2-\mathrm{Tg}$ animals after $\mathrm{PH}$ detected by Western blot and normalized with p85. (D-E) Representative Western blots and densitometric analysis of PCNA, cyclin D1 and $\mathrm{E}$ in Wt and COX-2 Tg mice after PH. Results are the means $\pm \mathrm{SD}$ of the five animals. ${ }^{*}, * *$ denotes $P<0.05$ and $P<0.001$ vs. the corresponding $\mathrm{Wt}$ condition treated under identical conditions, respectively. 
TABLE I. Plasma Levels of Liver Injury Markers.

\begin{tabular}{llcccc}
\hline Mice & AST (UI/l) & ALT (UI/l) & ALP (UI/l) & LDH (UI/) \\
\hline Wt & Saline & $84 \pm 16$ & $39 \pm 7$ & $355 \pm 66$ & $47 \pm 9$ \\
& LPS/D-GalN & $3750 \pm 694$ & $537 \pm 99$ & $400 \pm 74$ & $6381 \pm 1180$ \\
& LPS/D-GalN + DFU & $3697 \pm 684$ & ND & $529 \pm 98$ & ND \\
Tg & Saline & $71 \pm 12 *$ & $22 \pm 4$ & $279 \pm 48$ & $33 \pm 6$ \\
& LPS/D-GalN & $624 \pm 108^{*}$ & $66 \pm 11^{*}$ & $219 \pm 38$ & $734 \pm 127^{*}$ \\
& LPS/D-GalN + DFU & $1531 \pm 265^{*}$ & ND & $238 \pm 41$ & ND \\
\hline
\end{tabular}

Table I. Plasma levels of liver injury markers after LPS/D-GalN treatment.

Plasma levels of aminotransferases (AST, ALT), alkaline phosphatase (ALP) and lactate dehydrogenase $(\mathrm{LDH})$ were assayed spectrophotometrically after $6 \mathrm{~h}$ of treatment from the different groups of animals. ND, not determined. Results are mean \pm SD of five animals per condition. ${ }^{*} P<0.05 v s$. the corresponding Wt animals treated under identical conditions. ${ }^{\#} P<0.05$ vs. the corresponding Tg animals treated without DFU. 
TABLE II. Plasma Levels of Liver Injury Markers.

\begin{tabular}{clcccc}
\hline Mice & & AST (UI/l) & ALT (UI/l) & ALP (UI/l) & LDH (UI/l) \\
\hline \multirow{2}{*}{ Wt } & Saline & $84 \pm 16$ & $39 \pm 7$ & $355 \pm 66$ & $47 \pm 9$ \\
& ConA & $1372 \pm 254$ & $370 \pm 68$ & $276 \pm 51$ & $3438 \pm 636$ \\
\multirow{2}{*}{ Tg } & Saline & $71 \pm 12$ & $22 \pm 4$ & $279 \pm 48$ & $33 \pm 6$ \\
& ConA & $879 \pm 152^{*}$ & $64 \pm 11^{*}$ & $183 \pm 32$ & $1344 \pm 233^{*}$ \\
\hline
\end{tabular}

Table II. Plasma levels of liver injury markers after ConA treatment.

Plasma levels of AST, ALT, ALP and LDH were assayed spectrophotometrically after $8 \mathrm{~h}$ of treatment from the different groups of animals. Results are mean \pm SD of five animals per condition. ${ }^{*} P<0.05 v s$. the corresponding Wt animals treated under identical conditions. 
$\mathbf{A}$

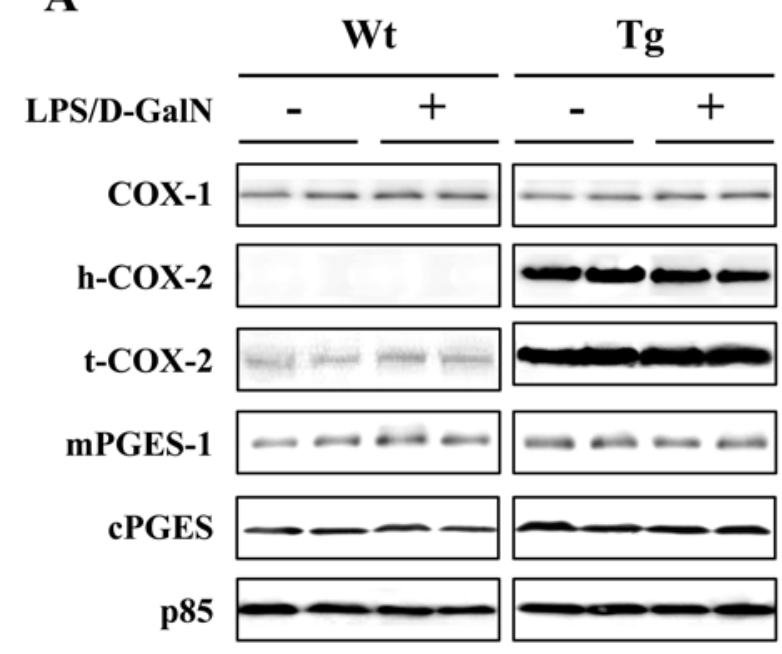

B

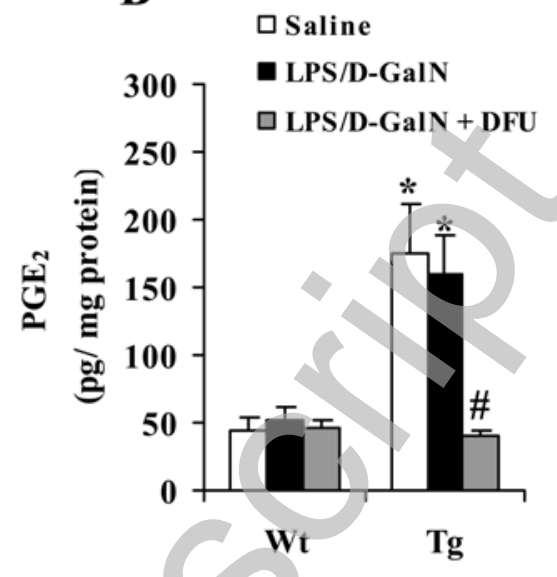


Biochemical Journal Immediate Publication. Published on 01 Aug 2008 as manuscript BJ20081224 rigure 2 .

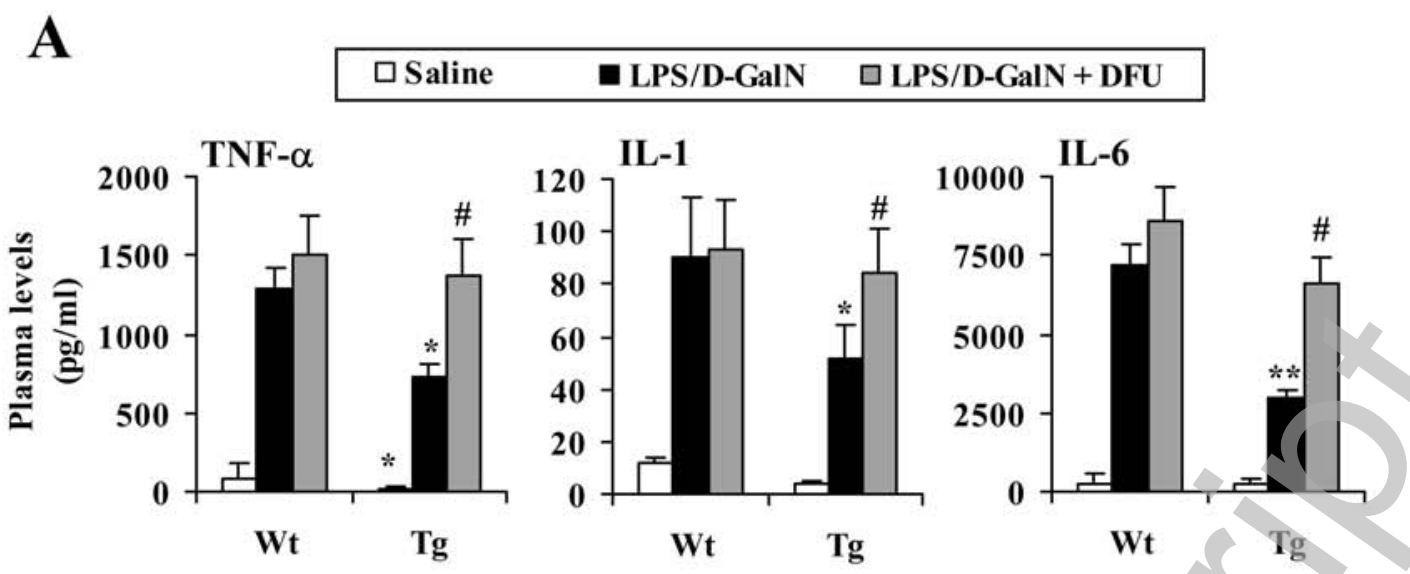

B

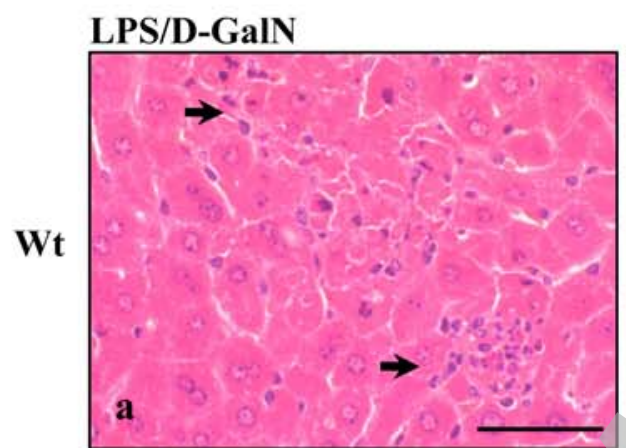

LPS/D-GalN+DFU

C
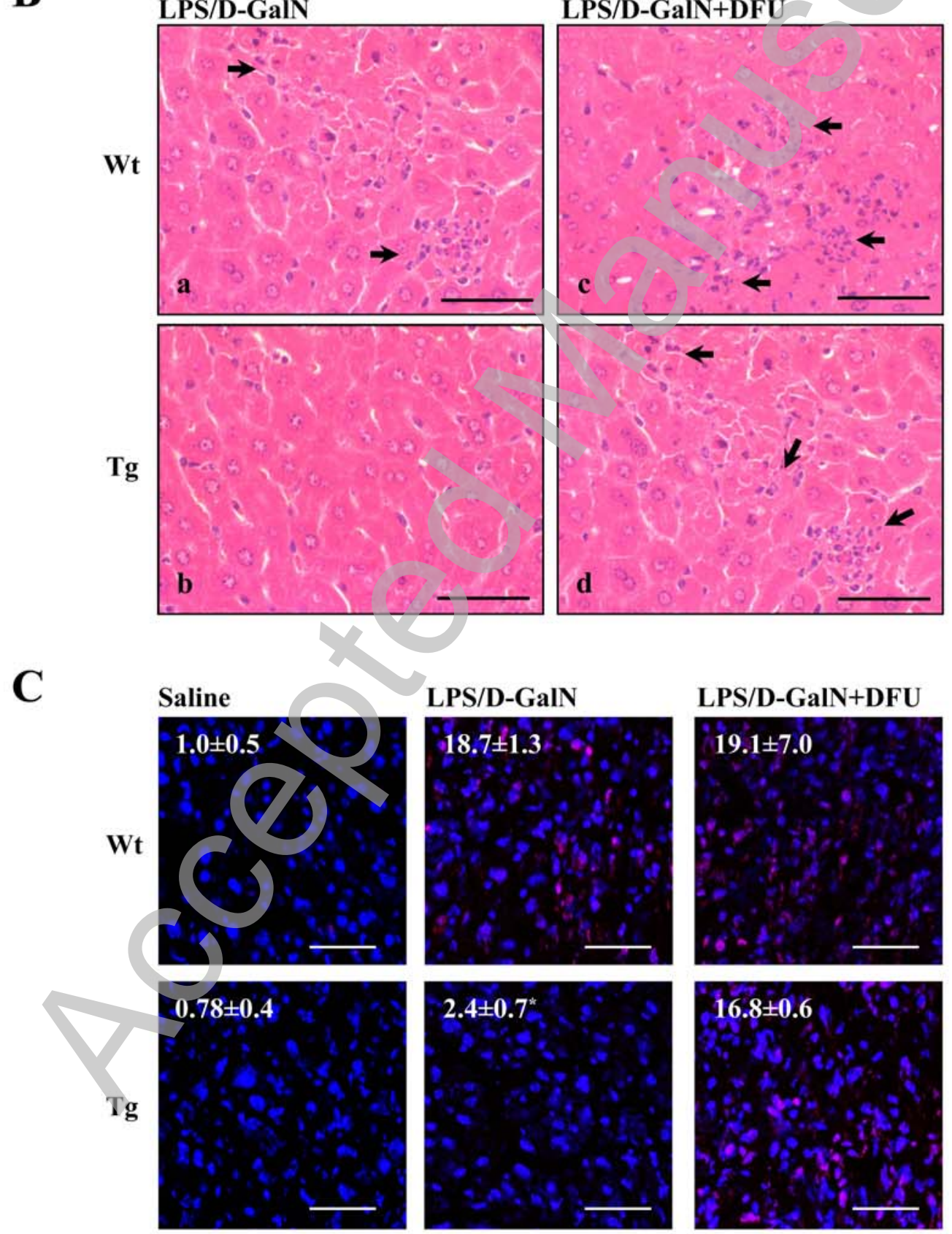
Biochemical Journal Immediate Publication. Published on 01 Aug 2008 as manuscript BJ20081224 Figure 3.

A

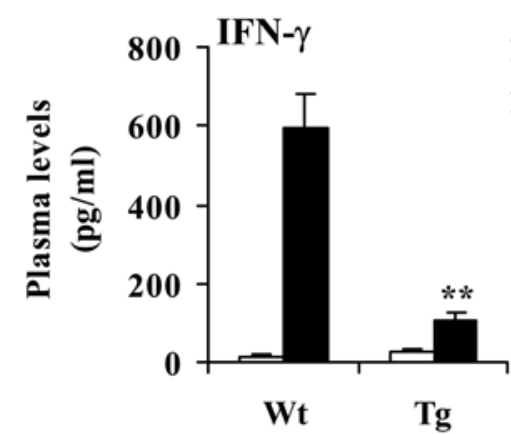

$\square$ ConA
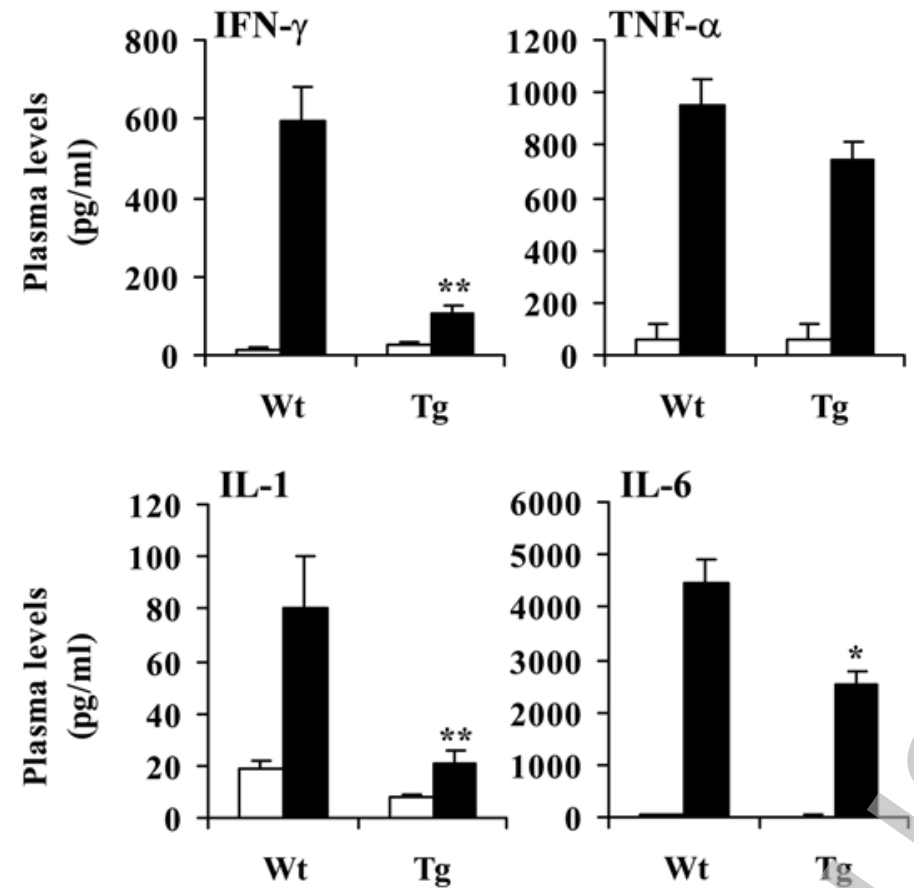

B

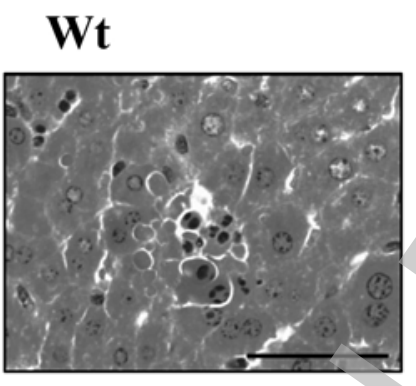

\section{Tg}

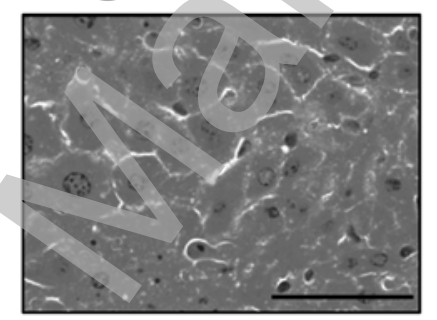


A

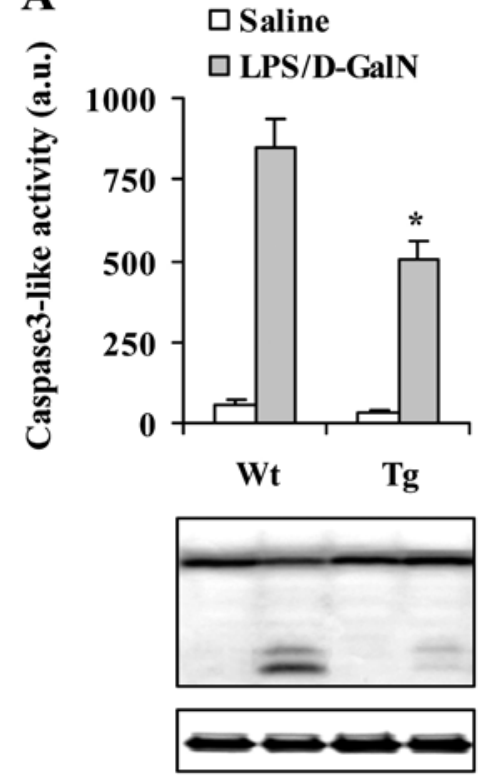

B

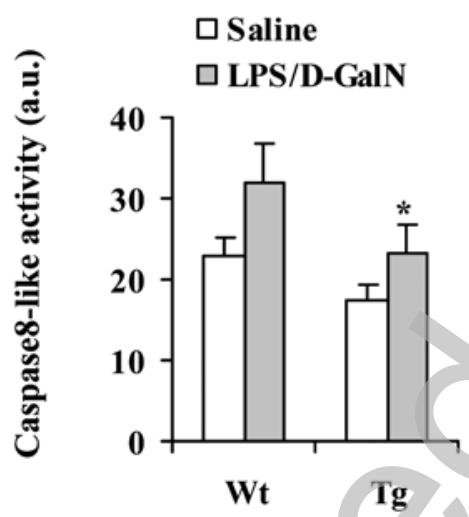

C

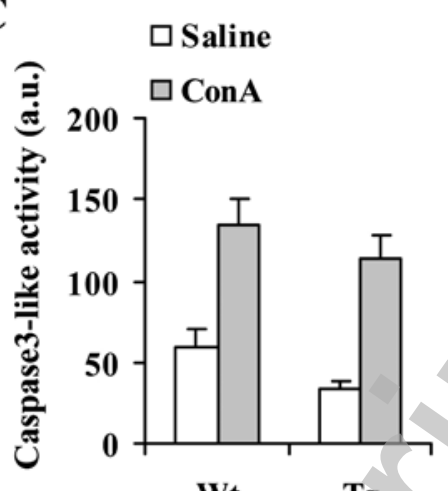

Wt

Tg

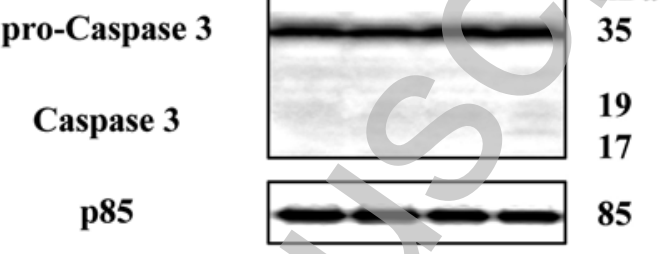

D

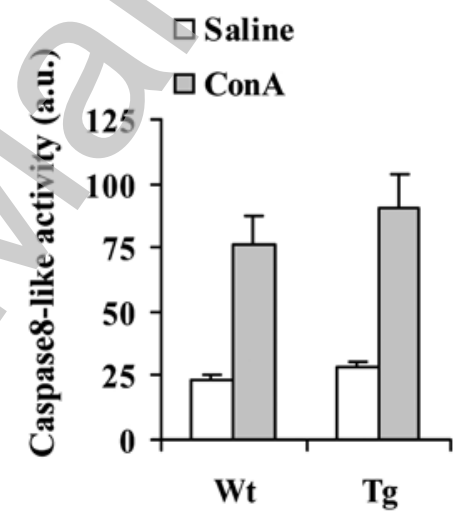


Figure 5.

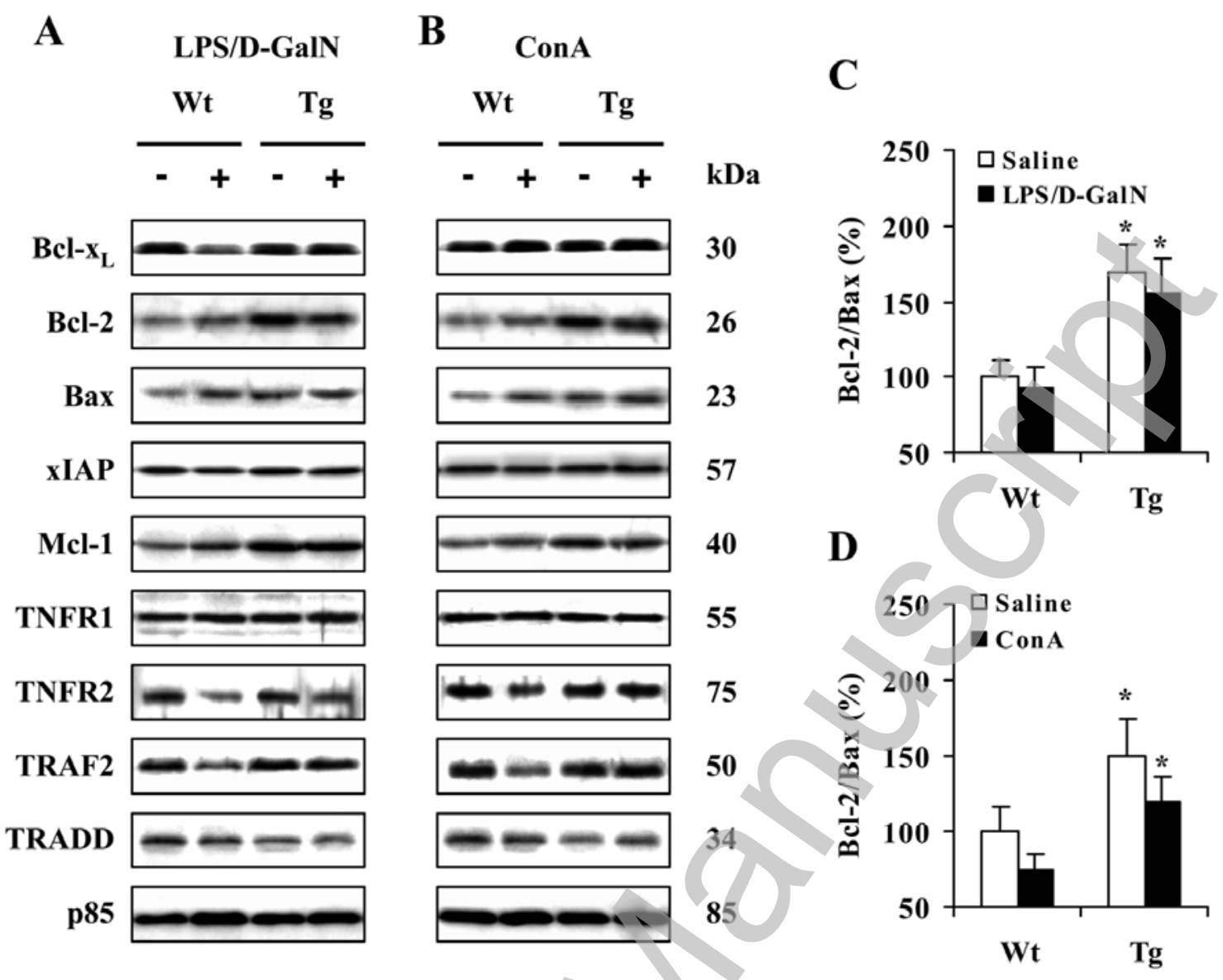

Licenced copy. Copying is not permitted, except with prior permission and as allowed by law. (C) 2008 The Authors Journal compilation (C) 2008 Biochemical Society 
A

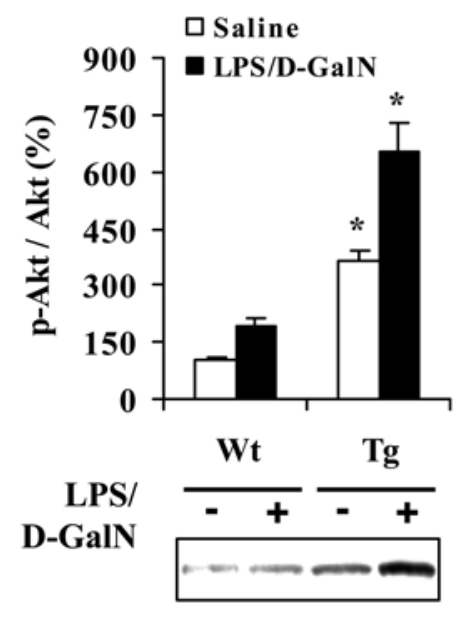

C

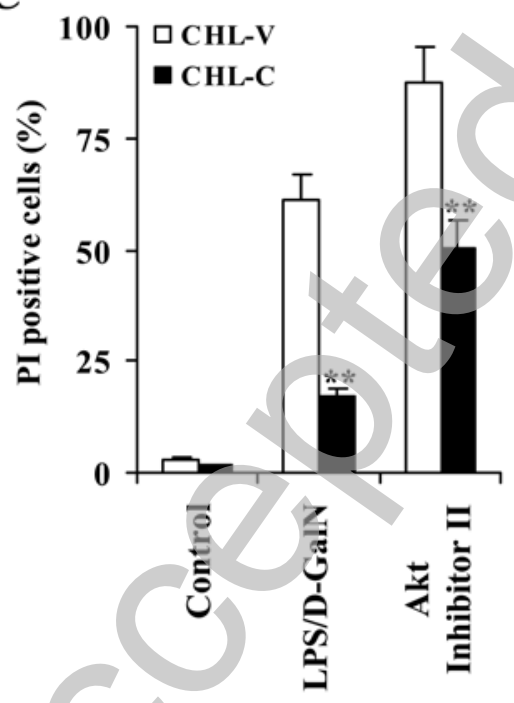

B
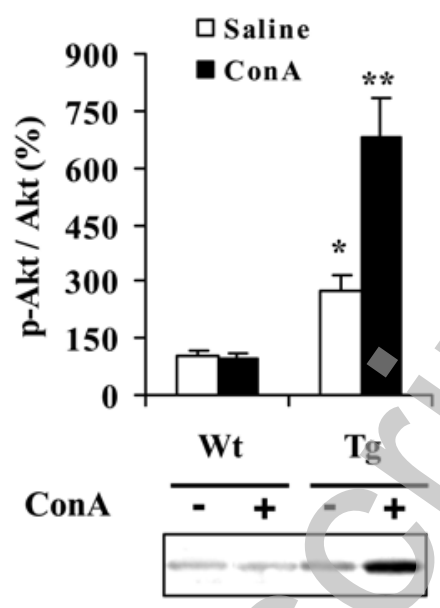

Akt

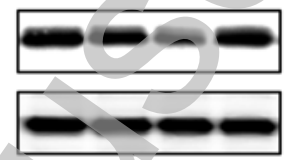

p85

p-AMPK $\alpha$

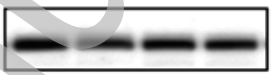

AMPK $\alpha$

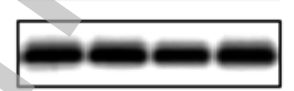

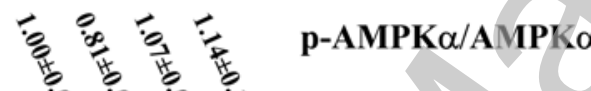

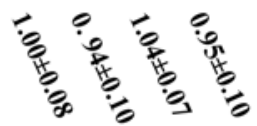


Biochemical Journal Immediate Publication. Published on 01 Aug 2008 as manuscript BJ20081224

Figure 7

A

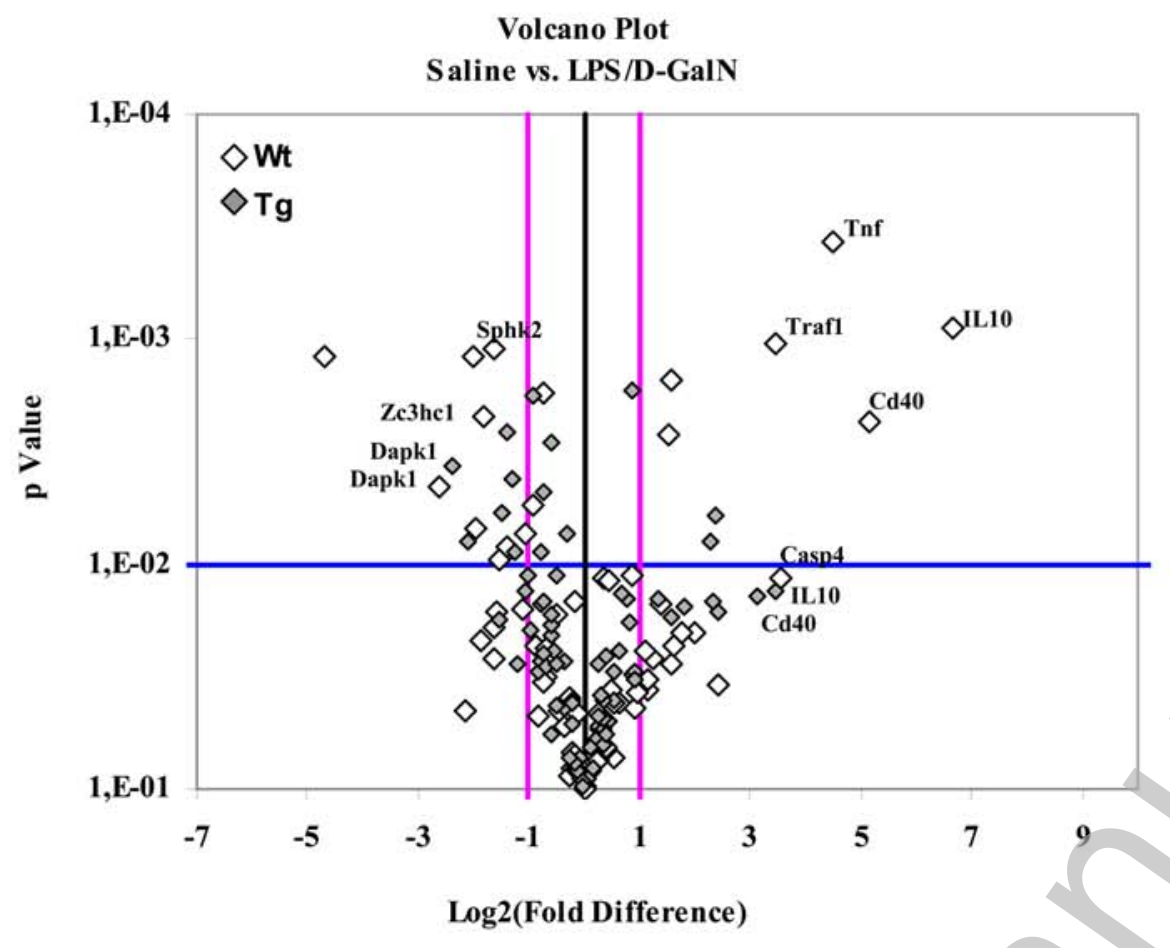

B

Fold Up/Down-Regulation Saline vs. LPS/D-GalN

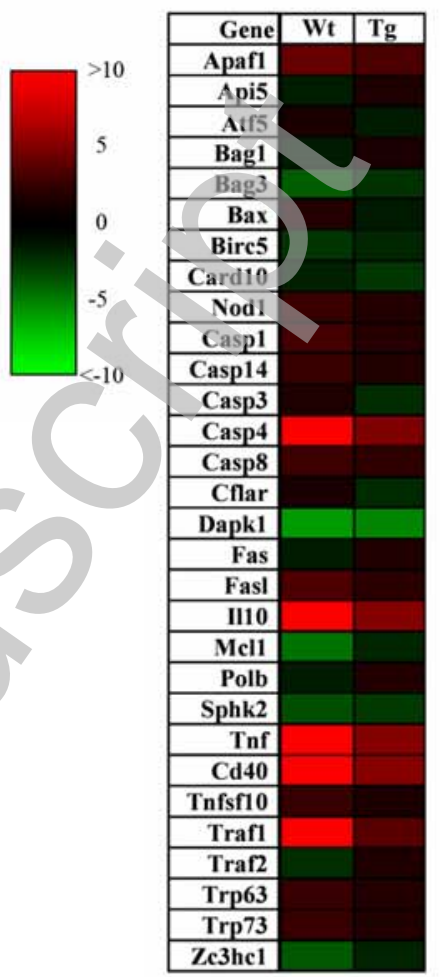


A

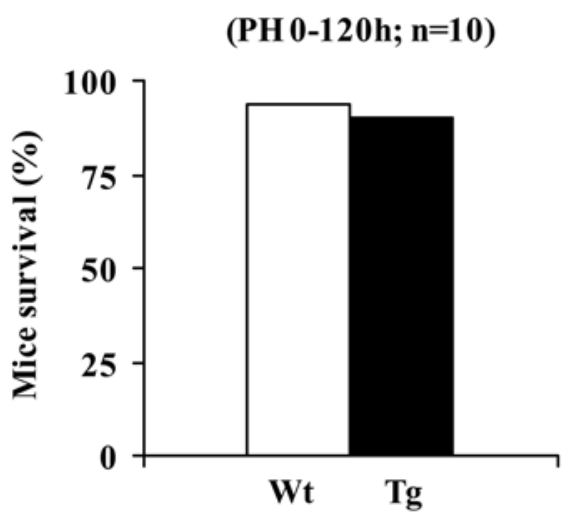

C

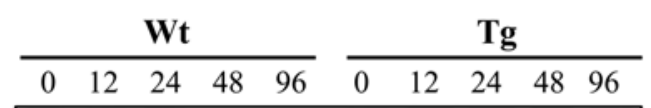

COX-2

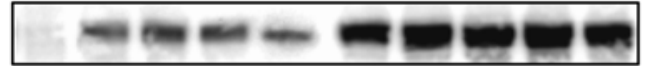

CoX-1 $-\ldots-\ldots$

mPGES $-\cdots-\cdots$

p85

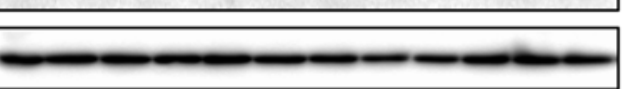

B

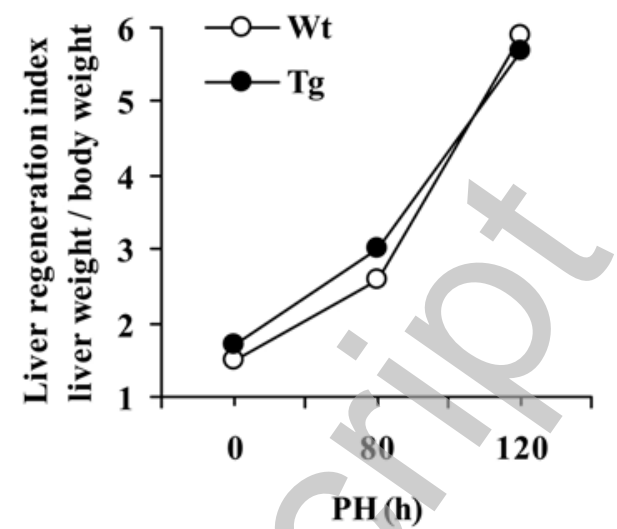

D

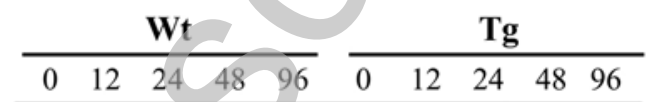

PCNA

Cyc D1

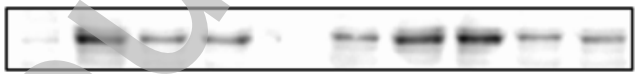

Cyc E

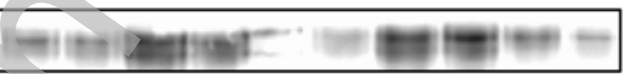

p85

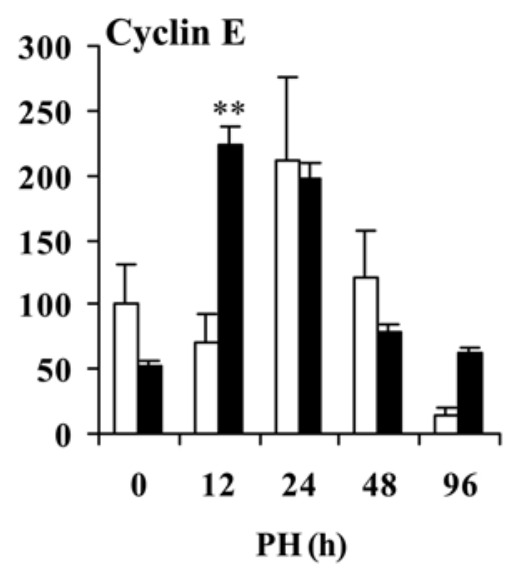

